A Smc5-13myc

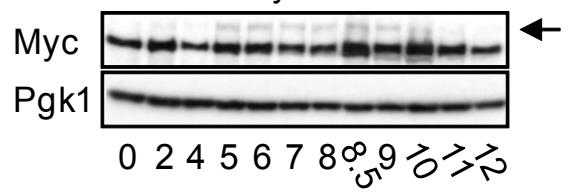

Nse4-TAP

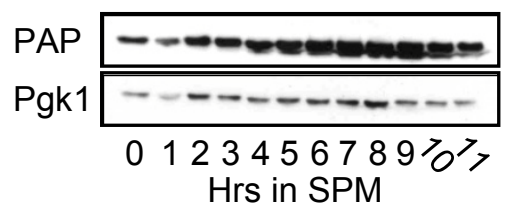

B
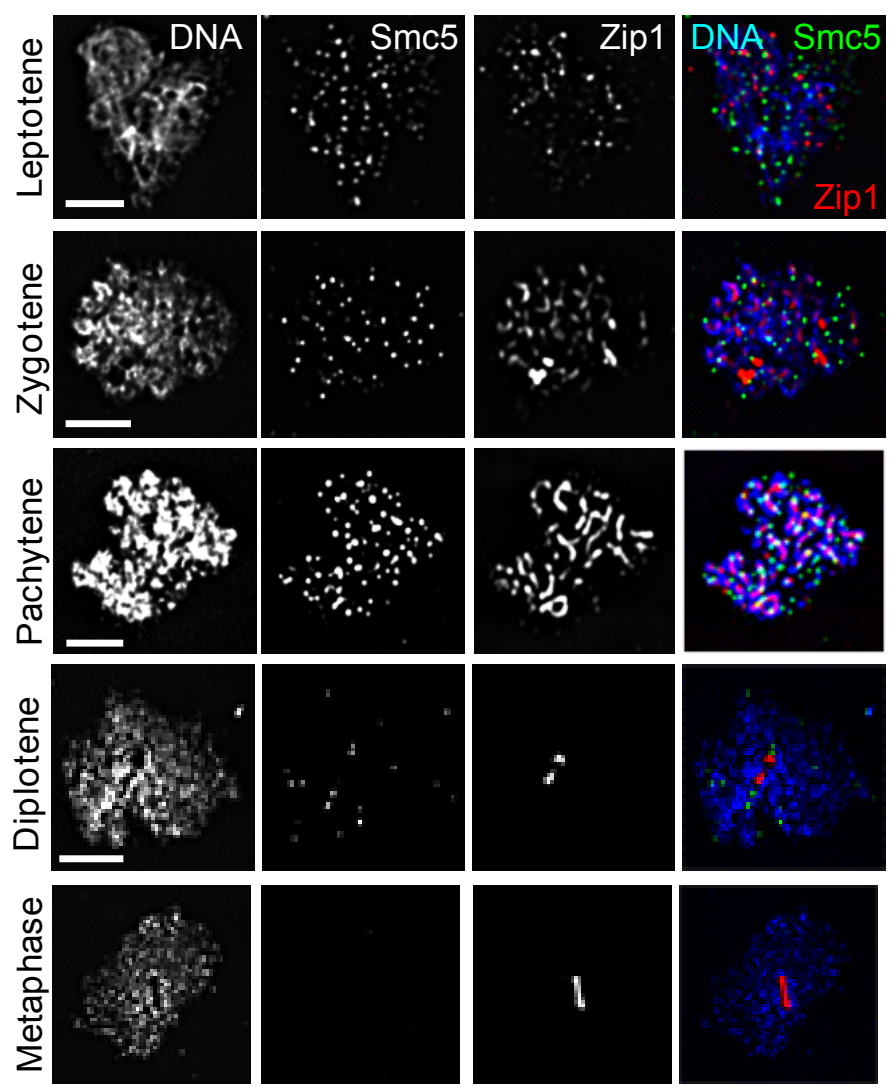

C

\section{rec8 8}
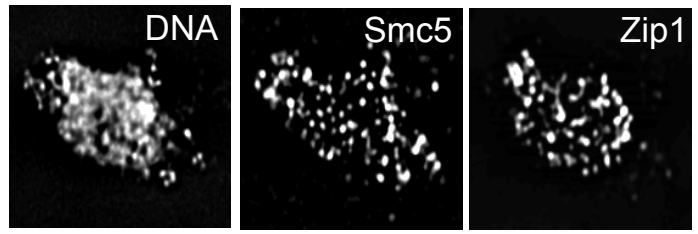

spo11ム
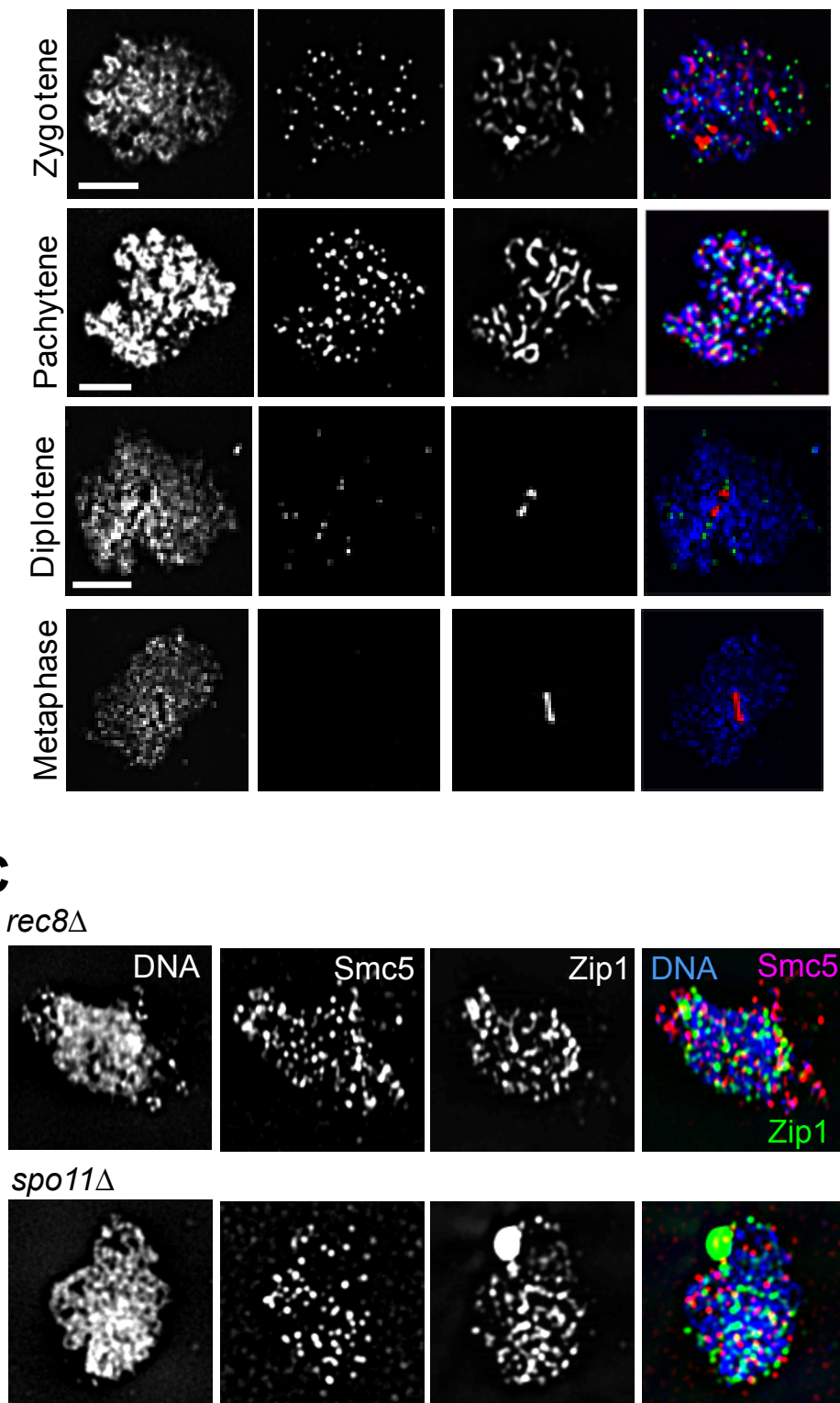

Zip1
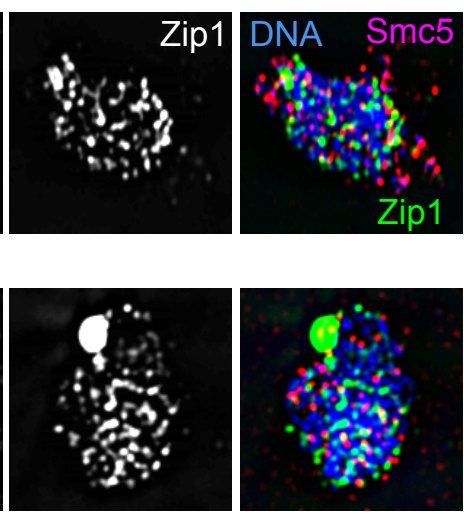

D

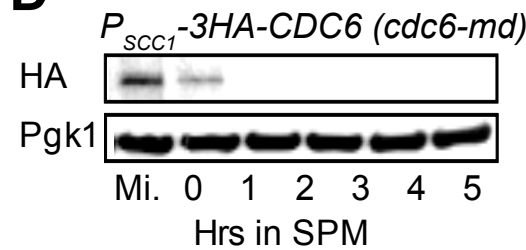

cdc6-md Smc5-13myc

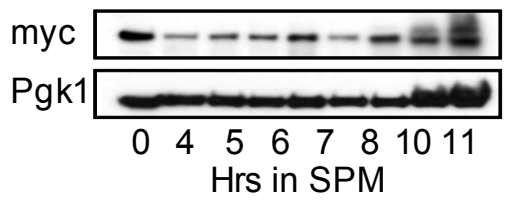

E
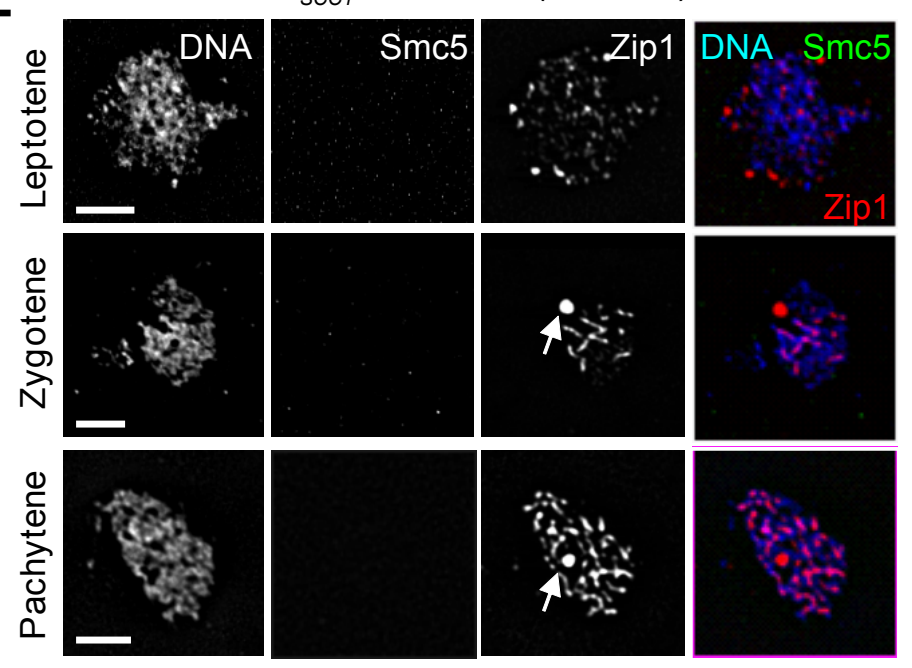

\section{F}

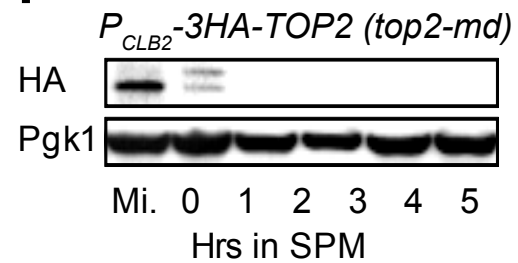

top2-md Smc5-13myc

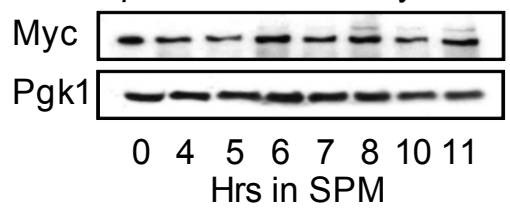

G $\quad P_{C L B 2}-3 H A-T O P 2$ (top2-md)
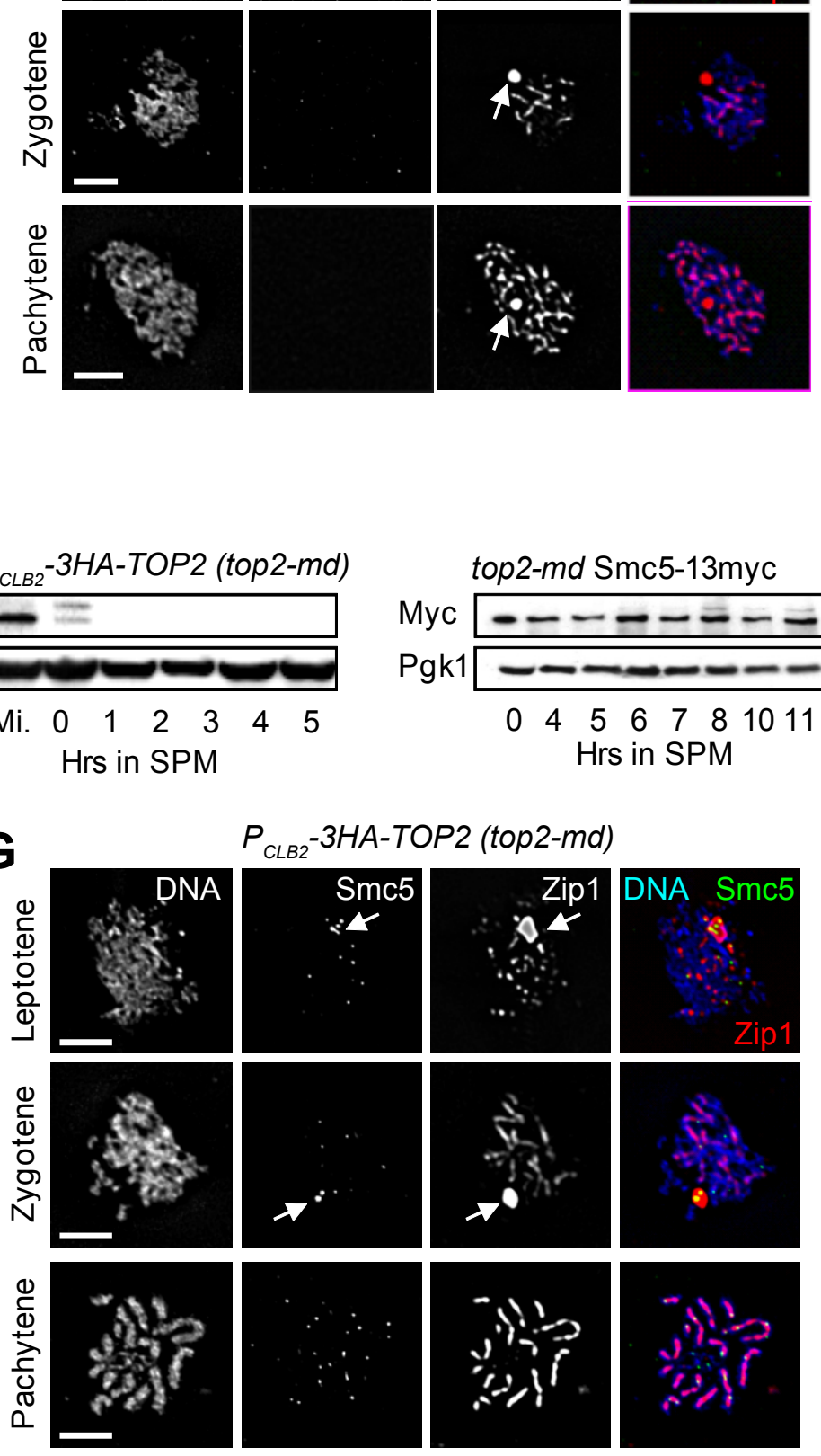